\title{
1 Projecting climate-driven shifts in demersal fish habitat in Iceland's waters
}

2 Authors: Julia G. Mason ${ }^{1,2}$, Pamela J. Woods ${ }^{3}$, Magnús Thorlacius ${ }^{3}$, Kristinn Guðnason ${ }^{3}$,

3 Vincent S. Saba ${ }^{4}$, Patrick J. Sullivan ${ }^{2,5}$, Kristin M. Kleisner ${ }^{1}$

4 1. Environmental Defense Fund, Boston, MA, USA 02108

5 2. Atkinson Center for Sustainability, Cornell University, Ithaca NY 14853

6 3. Marine and Freshwater Research Institute, Hafnarfjörður, Iceland

4. National Oceanic and Atmospheric Administration, National Marine Fisheries Service, Northeast Fisheries Science Center, Geophysical Fluid Dynamics Laboratory, Princeton University, Princeton, New Jersey, USA

5. Department of Natural Resources and the Environment, Cornell University, Ithaca NY 14853

Correspondence: jmason@edf.org

Keywords: Climate change, Generalized additive model, Suitable thermal habitat, Species

distribution modeling, Global climate model

\section{Abstract}

As climate change shifts marine species distribution and abundance worldwide, projecting local changes over decadal scales may be a valuable adaptive strategy for managers and industry. In Iceland, one of the top fish-producing nations in the world, long-term monitoring enables model simulations of groundfish species habitat distribution. We used generalized additive models to characterize suitable thermal habitat for 47 fish species in Iceland's waters. We then projected changes in thermal habitat by midcentury with an ensemble of five general circulation models from the Coupled Model Intercomparison Program 6 (CMIP6) and NOAA (CM2.6) and two scenarios (SSP 5-8.5 and SSP 2-4.5). We find a general northward shift in centroids of habitat

26 distribution, with variable regional dynamics among species. Species thermal affinity was the

27 most significant predictor of future habitat change, with warmer-water species more likely to see 
projected increases in suitable habitat. We present spatially explicit habitat change projections for commercially and culturally important species. These projections might serve as guideposts to inform long-term management decisions about regional and species-specific suitability for Iceland's fisheries, infrastructure investment, and risk evaluation under climate change.

\section{Introduction}

Climate change is shifting marine species distribution and abundance worldwide change intensifies (Molinos et al., 2016), with complex and unevenly distributed socialecological consequences (Golden et al., 2016; Lam et al., 2016; Pinsky et al., 2018; Sumaila et al., 2011). Alongside the urgent need for bold action to reduce greenhouse gas emissions is the need for adaptive management approaches to maintain desired fishery outcomes under changing and novel conditions. Researchers project that implementing management that accounts for changes in fish species productivity and distribution can improve outcomes for fishery catches

42 and profits under most climate scenarios (Free et al., 2020; Gaines et al., 2018). For fisheries

43 with adequate scientific and technical capacity, conducting forecasts and incorporating future

44 climate scenarios into management decisions is a key aspect of climate-adaptive management

45 (Free et al., 2020; Holsman et al., 2019; Karp et al., 2019; Pinsky \& Mantua, 2014). While seasonal and interannual forecasts may be of most immediate use for management and industry,

47 climate-scale projections allow managers and practitioners to evaluate risk, plan for future losses

48 or gains in suitability, and inform longer term decision-making processes such as national

49 legislation or international negotiations (Hobday et al., 2018; Holsman et al., 2019). 
In Iceland, the economic and cultural importance of fisheries and the sophistication of its

51 management and scientific systems mean that projecting future change in fish stocks could be a

52 key priority for achieving climate-adaptive fisheries (Kleisner et al. in press). Consistently

53 ranking among the top twenty marine fish capture producing countries worldwide (FAO, 2020),

54 Iceland is located in a highly productive transition zone between warm Atlantic and cold Polar

55 currents. The interactions of these currents create high spatial and temporal oceanographic

56 variability within Iceland's waters, and the ecosystem is highly sensitive to their dynamics

57 (Astthorsson et al., 2007). Environmental conditions have fluctuated over the past century in

58 relation to multidecadal oscillations and local atmospheric dynamics with profound ecological

59 and economic consequences: Relatively warm periods were associated with fishery booms that

60 drove the development of Iceland's commercial fisheries and economy, and cooler-water periods

61 (in combination with overfishing) associated with devastating fishery crashes (Astthorsson et al.,

62 2007; Ogilvie \& Jónsdóttir, 2000; Valtýsson \& Jónsson, 2018).

Recently, a warm anomaly from the mid-1990s to late 2010s drove substantial changes in

64 fish abundance and distribution around Iceland, including documentation of new species and

65 increases of warmer-water species (Astthorsson \& Palsson, 2006; Valdimarsson et al., 2012;

66 Valtýsson \& Jónsson, 2018). Particularly notorious was the abrupt expansion of Atlantic

67 mackerel (Scomber scombrus) into Iceland's waters (Olafur S. Astthorsson et al., 2012;

68 Olafsdottir et al., 2019) that quickly became an economic boon for Iceland, but led to

69 international political conflict over the fishing of the stock (Spijkers \& Boonstra, 2017).

70 Researchers also noted significant shifts in groundfish distribution and community assemblage,

71 with heterogeneous regional trends associated with oceanographic conditions and the influence 
72 of coastal fjord systems on predator-prey dynamics (Jónsdóttir et al., 2019; Stefánsdóttir, 2008;

73 Stefánsdóttir, 2019).

Given these past temperature-related changes, a logical next step might be to project how future change might affect fish species abundance and distribution. Global studies have projected that Iceland, like other high-latitude countries, could be a climate "winner," potentially experiencing increased biodiversity and fisheries catch potential as warmer waters move fish poleward (Cheung et al., 2009; Molinos et al., 2016). However, given the highly local and variable dynamics of Iceland climatic conditions and differing ecological, economic, and cultural importance of its fish species, higher-resolution projections indicating specific species and

81 regional dynamics could be more applicable for fisheries managers and industry. Campana et al.

82 (2020) used Iceland bottom trawl survey data to model fish habitat and projected that a uniform $1^{\circ} \mathrm{C}$ increase in bottom temperature would drive a general northward shift in habitat distribution, with significant variation across species and quadrants of the exclusive economic zone (EEZ). The authors noted a high level of regional and temporal variation in past warming trends and warned that future warning is unlikely to be homogenous nor linear.

88 fisheries dependent data since the 1980s, allowing for detailed analyses of species abundance and distribution in relation to environmental conditions that can inform future projections. These

90 long-term monitoring data are ideal for a common but data-intensive approach to anticipating

91 regional or global species distribution shifts: pairing statistical models of species suitable habitat

92 with global climate model outputs (Stock et al., 2011). Given the uncertainty inherent to

93 projecting both the dynamics of the global climate and the human actions and policies that

94 influence those dynamics, using an ensemble of climate models across different scenarios is 
advised (Morley et al., 2018, 2020). Here we use long-term fisheries independent trawl data and an ensemble of the newest generation of global climate models from the Coupled Model Intercomparison Project (CMIP6) to project how future climate change will affect suitable thermal habitat of 47 species in Iceland's waters at a $0.25^{\circ} \times 0.25^{\circ}$ resolution. These spatially explicit climate projections can more directly inform Iceland's fishing industry and fisheries management's needs for adapting to climate-driven changes in fish distribution, and illustrate to other nations and regions how these projections might be considered in long-term climateadaptive management.

\section{Methods}

Projecting future temperature changes in Iceland's waters

We used a suite of global climate models to project future ocean surface and bottom temperatures in Iceland's waters, including a high-resolution global climate model (CM2.6 from the National Oceanic and Atmospheric Administration Geophysical Fluid Dynamics Laboratory, NOAA GFDL) and four coarser global climate models from the Coupled Model Intercomparison Project 6 (CMIP6). Researchers have found that CM2.6 (10-km ocean resolution) resolves the ocean circulation in the Northwest Atlantic more realistically than coarser models (Saba et al., 2016). However, this model has a cold bias in sea surface and bottom temperature in Iceland's waters in the historical period from 1982-2012, so we selected the highest resolution CMIP6 models that have a range of cold and warm biases to complement the higher resolution CM2.6. These were GFDL CM4 (25-km ocean resolution) from the National Oceanic and Atmospheric Administration Geophysical Fluid Dynamics Laboratory, U.S.A; CNRM-CM6 (25-km ocean 
117 resolution) from the Centre National de Recherches Meteorologiques and Centre Europeen de

118 Recherche et de Formation Avancee en Calcul Scientifique, France; HadGEM3-GC31 (100-km

119 ocean resolution) from the Met Office Hadley Centre, U.K.; and IPSL-CM6A-LR (100-km

120 ocean resolution) from L’Institut Pierre Simon Laplace, France. We downloaded CMIP6 data

121 using the xarray package (version 0.15.1) in Python (version 3.7.6) (Hoyer \& Hamman, 2017).

The CMIP6 models use future scenario simulations that combine the Representative

Concentration Pathways (RCPs) of radiative forcings used in the Intergovernmental Panel on

124 Climate Change's Fifth Assessment Report (IPCC AR5) with Shared Socioeconomic Pathways

125 (SSPs) of societal development (Eyring et al., 2016; O’Neill et al., 2017). We examined two

126 future scenarios for the years 2015-2100: SSP 2-4.5, a "middle of the road" scenario where

127 countries continue along historical social, economic, and technological development trajectories

128 as they strive toward sustainable development goals; and SSP 5-8.5, a "fossil-fueled

129 development" scenario where accelerated economic growth emphasizes fossil fuels (O'Neill et

al., 2017). The CM2.6 projects an idealized transient climate response (1\% per year increase in

131 atmospheric $\mathrm{CO}_{2}$ ) simulation over 80 years, where the last 20 years are comparable to years

2061-2080 of SSP 5-8.5. We thus focused on this 2061-2080 period for our future projections.

We standardized the models using the "delta method," where we calculated the difference

134 between each model's monthly projections and modeled historical control (mean of 1985-2015),

135 and then added these deltas to a standard climatology (Anandhi et al., 2011; Kleisner et al., 2017;

136 Morley et al., 2018). We used a sea surface temperature (SST) climatology from daily NOAA

137 Optimum Interpolated Sea Surface Temperature (OISST) data from 1982-2012 and a bottom

138 temperature climatology from the NOAA Greenland-Iceland-Norwegian Seas Regional

139 Climatology version 2 (GINS RC v2) from 1985-2012 (Seidov et al. 2013). All projections were 
140 interpolated to a standard $0.25^{\circ} \times 0.25^{\circ}$ grid to match the OISST resolution. We ran a monthly

141 SST and bottom temperature hindcast for the years 2000-2018 using the Mercator Ocean Global

142 Reanalysis (GLORYS) dataset from the Copernicus Marine Environment Monitoring Service

143 and a projection for the years 2061-2080 for each the five models and two scenarios on a

144 projection grid of the $2,3120.25^{\circ}$ cells in Iceland's EEZ.

Modeling species thermal habitat

The Icelandic Marine and Freshwater Research Institute (MFRI) conducts annual

148 standardized bottom trawl surveys in the spring and autumn to inform groundfish stock

149 assessments. The spring survey has been conducted since 1985 at about 590 fixed stations

150 covering Iceland's continental shelf to 500m depth (Solmundsson et al., 2020). The autumn

151 survey, initiated in 1996 and expanded in 2000, covers about 400 fixed stations that additionally

152 include deeper waters along the continental slope (400-1500m; Campana et al. 2020). Fish

153 lengths and standard weight conversions are used to calculate biomass (kg) per nautical mile.

154 Surface temperature and bottom temperature are also measured in situ. We used surveys through

155 March 2020, excluding the autumn survey before it was expanded in 2000 and 2011 when a

156 labor strike interrupted the survey, for $n=27,524$ total survey tows (Figure 1 ). We combined the

157 spring and autumn surveys to better account for the full thermal envelope each species

158 experiences throughout the year (Kleisner et al., 2017).

159 We modeled individual species distributions with two-stage generalized additive models

160 (GAMs), using the mgcv package (version 1.8.33) in R (version 4.0.2) (Wood, 2011). The first

161 stage was a presence-absence model with a binomial error distribution, and the second stage was 
162 a biomass given presence model using a log-link transform on non-zero observations with a 163 gaussian error distribution. For both stages, we included a penalized likelihood to reduce model

164 complexity (Morley et al., 2018; Wood, 2006). We calculated suitable thermal habitat as the

165 product of the presence-absence model predictions, the back-transformed log-biomass model

166 predictions, and a smearing estimate (the mean of the log-biomass model residuals) to correct for

167 retransformation bias (Duan 1983; Kleisner et al., 2017; Morley et al., 2018). This suitable

168 thermal habitat value does not directly represent species abundance, but rather the potential

169 suitable habitat and species density solely based on model predictor variables (Kleisner et al., $170 \quad$ 2017; Morley et al., 2018).

The predictor variables for the models included tow and environmental information from

172 the trawl surveys and more complex temperature variables from GLORYS. From the surveys, we

173 used in situ surface and bottom temperature and the starting depth of the tow. We used GLORYS

174 temperature data to characterize broader spatial and temporal aspects of thermal habitat that

175 could influence species distribution, including the annual minimum and maximum surface and

176 bottom temperature (that is, the minimum or maximum temperature over the preceding twelve

177 months in the $0.25^{\circ} \times 0.25^{\circ}$ cell where the tow was conducted) and spatial standard deviation of

178 surface and bottom temperature (using a $3 \times 3$ window around each $0.25^{\circ} \times 0.25^{\circ}$ cell) to

179 approximate frontal activity (Abrahms et al., 2019; Morley et al., 2018), which is known to

180 influence species distribution in Iceland's waters (Astthorsson et al., 2007). We removed the

181 annual minimum bottom temperature as a predictor variable because it was highly correlated

182 with the survey in situ bottom temperature (Spearman's rho $=0.77$ ).

To account for habitat suitability factors not captured by depth and temperature, we

184 added Bormicon regions (Figure 1), which are habitat zones used in MFRI's multispecies 
The GLORYS data were available from 1993-2018, so the final models were fitted with n

modelling efforts (Stefansson, 2004), as a parametric term. These regions were delineated based on topography (the depth contour of the continental shelf and submarine ridges), hydrography (salinity distribution and mixing patterns), and general patterns of spawning, migration, and fishing effort for key demersal species (Stefansson \& Palsson, 1997). We selected these regions based on their management relevance and in the absence of more detailed habitat quality data but recognize risks of tautology in using these regions to simulate species distribution. We performed additional tests of the suitability of this predictor during initial model selection and determined that it improved model performance in terms of prediction error, deviance explained, and Akaike's Information Criterion (AIC) for the majority of species. The fact that there are relatively few survey tows in the offshore regions also limits predictive performance, so we focus our subsequent results and discussion on habitat dynamics along the continental shelf and provide the caveat that this variable should be interpreted with caution, particularly for any species for which models project offshore habitat changes.

Thus, the final model formulas were as follows, where $\mathrm{s}()$ represents a thin plate spline smooth term:

$$
\begin{aligned}
& \text { Presence } \sim \text { intercept }+ \text { Bormicon region }+\mathrm{s}(\text { tow depth })+\mathrm{s}(\mathrm{SST})+\mathrm{s}(\text { bottom } \\
& \text { temperature })+\mathrm{s}(\min \mathrm{SST})+\mathrm{s}(\max \mathrm{SST})+\mathrm{s}(\mathrm{sd} \mathrm{SST})+\mathrm{s}(\max \mathrm{BT})+\mathrm{s}(\mathrm{sd} \mathrm{BT})
\end{aligned}
$$

$$
\text { Log-biomass }(\mathrm{kg}) \sim \text { intercept }+ \text { Bormicon region }+\mathrm{s}(\text { tow depth })+\mathrm{s}(\mathrm{SST})+
$$$$
\mathrm{s}(\text { bottom temperature })+\mathrm{s}(\min \mathrm{SST})+\mathrm{s}(\max \mathrm{SST})+\mathrm{s}(\mathrm{sd} \mathrm{SST})+\mathrm{s}(\max \mathrm{BT})+
$$
$\mathrm{s}(\mathrm{sd} \mathrm{BT})$

$206=19759$ tows with all predictor data available. For species with no presences observed in a 
207

208

209

210

particular Bormicon region, we randomly replaced $10 \%$ of the tows in those regions with nearzero $\left(1^{-10}\right)$ biomass values to allow log-biomass projections in those areas, following Morely et al. (2018). Because these surveys were designed to sample demersal fish, we removed invertebrate and pelagic species for analysis. We ran models for 56 fish species with sufficient observations for the model parameters.

We assessed model performance by training the presence-absence models with tows through 2013 (approximately $80 \%$ of the tows), and testing predictions on the remaining $20 \%$ of the tows. We assessed presence-absence models using true skill statistic (TSS), a measure suited to spatial presence-absence prediction performance, where a score of 1 represents perfect agreement and a score $<0$ is no better than random (Allouche et al., 2006). All species had a TSS score $>0.25$, so we did not remove any species from analysis based on this metric. To evaluate the importance of each predictor variable in contributing to model explanatory power, we compared the percent deviance explained from the full model and a model with that covariate dropped for each species.

We considered the suitability of a temperature-based model by comparing the prediction error in the combined presence-absence and log-biomass thermal suitable habitat predictions with that of a "naïve" model with temperature variables removed (i.e., just depth and Bormicon region as predictors). Models were considered suitable if the ratio of the full model to naïve model error was $<1$ and the Diebold-Mariano test p-value was < 0.05 (see Kleisner et al., 2017). We removed nine species from analysis based on this assessment and present results for the 47 remaining species. We performed these tests using the dismo package (version 1.3.2) in $\mathrm{R}$ (Hijmans et al., 2020). Other model results reported (deviance explained, suitable thermal habitat 
229 values) are based on the models fitted on all data, not split into training and testing. See

230 supplemental information for model performance results for all species.

231

232

233

234

235

236

237

238

239

240

241

242

243

\section{Projecting future thermal habitat}

We calculated the amount of available suitable habitat as the sum of all modeled thermal habitat values in the full EEZ projection grid (Morley et al., 2018). We compared the mean available habitat in the historical period (2000-2018) with the future period (2061-2080) for each species. Because some changes were quite large (orders of magnitude), we present $\log 10 \mathrm{x}$-fold change (log (mean future thermal habitat / mean historical thermal habitat)) so that relative increases and decreases can be compared. We calculated the centroid of distribution for each species as mean latitude and longitude weighted by the modeled thermal habitat value, and calculated the distance $(\mathrm{km})$ and direction (degrees) shifted between the historical and future period with the geosphere package (version 1.5.10) in R (Hijmans, 2019). Additionally, we calculated the shifts in warm and cold edges of species distributions as the difference in the $95^{\text {th }}$ and $5^{\text {th }}$ respective percentile latitude of thermal habitat values $>0.05$ (Fredston-Hermann et al., 2020).

We grouped species by thermal affinity indices outlined in Campana et al. (2020), based on bottom temperatures and depths from the trawl surveys. We calculated thermal bias as the difference in median biomass-weighted bottom temperature for each species and the median bottom temperature of all survey tows, stenothermal index as the range of $5^{\text {th }}$ and $95^{\text {th }}$ percentiles of those biomass-weighted bottom temperatures for each species, and depth as the biomassweighted median tow depth for each species. Because the spring and autumn surveys sample different areas and depths, we calculated separate index values for each season and took a weighted mean based on the number of observations in each season. Following Campana et al. 
252 (2020), we categorized species into warm water (positive thermal bias), cool water $\left(-3^{\circ} \mathrm{C}\right.$ to $0^{\circ} \mathrm{C}$

253 thermal bias), and cold water $\left(<-3^{\circ} \mathrm{C}\right.$ thermal bias $)$ niches. We tested associations between

254 thermal affinity indices and projected shifts in thermal habitat availability and distribution with

255 ordinary least squares regression.

256 Results

257 Projected climate change

The projected climate model deltas resulted in a mean increase in surface temperatures in

259 Iceland's EEZ of $1.96^{\circ} \mathrm{C}$ for SSP $2-4.5$ (ranging from $0.76^{\circ} \mathrm{C}, \mathrm{CNRM}$ to $2.40^{\circ} \mathrm{C}, \mathrm{MOHC}$ ) and

$2.40^{\circ} \mathrm{C}$ for SSP $5-8.5$ (ranging from $1.00^{\circ} \mathrm{C}, \mathrm{CM} 2.6$ to $3.40^{\circ} \mathrm{C}$, IPSL) by $2061-2080$. For bottom

261 temperatures, the mean projected increase for $2061-2080$ was $0.06^{\circ} \mathrm{C}$ for SSP $2-4.5$ (ranging

262 from $-1.5^{\circ} \mathrm{C}$, GFDL to $1.21^{\circ} \mathrm{C}$, IPSL) and $0.20^{\circ} \mathrm{C}$ for SSP $5-8.5$ (ranging from $-1.35^{\circ} \mathrm{C}$, GFDL to

$2631.47^{\circ} \mathrm{C}$, IPSL) in 2061-2080 (see supplemental information for time series of individual climate

264 model projections). Spatially, surface warming was projected throughout Iceland's EEZ and

265 most pronounced in offshore northeast waters for both scenarios (Figure 2a). The variation

266 among climate model surface temperature projections was also highest in Iceland's northern

267 waters, which likely reflects uncertainty in the mixing dynamics between Atlantic and polar

268 waters (Figure 2b). Bottom temperature deltas showed cooling in Iceland's southern waters

269 beyond the continental shelf, and concentrated warming along the northern shelf and east along

270 the Iceland-Faroes ridge in the southeast (Figure 2c). Variation among models was highest in the

271 east where warming is most pronounced, as well as offshore southern waters (Figure 2d). 
The presence-absence GAMs explained mean $44 \%$ of deviance (sd 16; range 10-81)

274

275

276

277

278

279

280

281

282

283

284

285

286

287

288

289

290

291

292

293

294

295

across the 47 species and had a mean TSS of 0.68 (sd 0.15 , range $0.36-0.95$ ). The log-biomass models explained mean $31 \%$ of deviance (sd 15, range 10-72). Tow depth and Bormicon region contributed the most to variance explained in both the presence-absence and log-biomass models. Models fitted without depth lost mean $12.9 \%$ variance explained for presence-absence (sd 9.11, range -2.05-32.1) and 5.5\% for log-biomass (sd 4.64, range -0.05-16.3). Models fitted without Bormicon region lost mean 10.5\% (sd 9.51, range -4.04-32.0) and 2.8\% (sd 1.74, range 0.14 -7.02) variance explained in presence-absence and log-biomass models, respectively. For the presence-absence models, the remaining temperature variables contributed between $8.9-9.6 \%$ variance explained on average, whereas for log-biomass models, lost variance explained was minimal, ranging from $0.2 \%$ for SST standard deviation and maximum to $0.86 \%$ for bottom temperature.

Warmer water species were generally projected to see an increase in suitable thermal habitat in 2061-2080 relative to 2000-2018, while cold and cool water species were generally projected to see a decrease in habitat (Figure 3). The magnitude of decreases was higher than the magnitude of increases, and patterns were similar across the two scenarios. Thirteen species had a projected increase in habitat for all models for SSP 2-4.5 and fifteen for SSP 5-8.5, whereas fifteen species had a projected decrease in habitat for all models in SSP 2-4.5 and sixteen for SSP 5-8.5. Thermal bias was significantly positively correlated with median change in projected suitable habitat for SSP 5-8.5 (adjusted $\mathrm{r}^{2}=0.12, \mathrm{p}<0.01$; for SSP 2-4.5, adjusted $\mathrm{r}^{2}=0.03$ and $\mathrm{p}=0.13$ ), whereas stenothermic index and median depth did not show a significant relationship with projected suitable thermal habitat change in either scenario (stenothermic index: $p=0.13$, 0.10; median depth: $\mathrm{p}=0.12,0.37)$. 
These projected habitat suitability shifts were spatially heterogeneous within Iceland's waters, with most species showing relatively localized increases and/or decreases (Figure 4). Cod

(Gadus morhua), saithe (Pollachius virens), and redfish (Sebastes marinus), key commercial

species, showed increases along Iceland's northern continental shelf. For cod, a cool water suitability decreases in the southwest and southeast (Figure 4a). Redfish showed a pronounced decrease in southwest offshore waters. Long rough dab (Hippoglossoides platessoides), a cool water species, showed nearly the opposite pattern to cod, with decreases along the northern continental shelf and increases in the south/southeast (for SSP 2-4.5) (Figure 4b). Whiting (Merlangius merlangus), along with several other warm-water species including monkfish 
319 Species with a higher thermal bias (i.e. warmer water species) were significantly more likely to

320 see northward movement of the cold edge of their range $\left(\operatorname{adj} r^{2}=0.10, p=0.02\right.$ for SSP 2-4.5,

321 adj $\mathrm{r}^{2}=0.14, \mathrm{p}=0.005$ for SSP 5-8.5), but there were no significant relationships observed for

322 movement of the southern warm range edge or with other thermal affinity indices.

\section{Discussion}

These results corroborate previous projections that future climate change could result in significant shifts in fish species abundance and distribution in Iceland's waters, and further

327 illustrate potential variability in responses among species and regions. Consistent with global

328 hypotheses and Campana et al. (2020)'s analyses, our results indicate an overall northward shift

329 in center of biomass distribution for Iceland's demersal fish species, with warmer water species

330 more likely to expand the cold edge of their range. Species thermal bias was a more significant

331 predictor of future habitat suitability change than stenothermic index or depth preference, results

332 also similar to Campana et al. (2020)'s findings. In general, our analyses suggest similar trends

333 to those observed during the mid-1990s warming period (Valtýsson \& Jónsson, 2018) could be

334 expected by midcentury, with many warmer water species likely to experience overall increases

335 in suitable thermal habitat in Iceland's EEZ. However, these patterns are localized and may be

336 accompanied by regional decreases.

It is encouraging that many commercially important species are projected to see increases

338 in suitable habitat in Iceland's waters. However, regional heterogeneity in habitat suitability

339 changes may be of interest to managers and the fishing industry. For example, the overall

340 increase in habitat suitability for cod, a flagship commercial species for Iceland, is largely along 
341 the northern coast, where fishing capacity and infrastructure has declined following industry

342 consolidation (Kokorsch \& Benediktsson, 2018). Meanwhile, the capital region and western

343 coast where cod catches have historically been highest may see decreases under the high- $\mathrm{CO}_{2}$

344 emission scenario. Fishers in these waters may see cod supplemented by warmer-water species

345 such as monkfish and megrim. The impact of these shifts may be felt unevenly within the fishing

346 industry as larger companies with more technological capacity are less dependent on proximity

347 to fishing grounds than smaller companies (Edvardsson et al. 2018). Local small boat operations

348 could be further disadvantaged by the projected decreased habitat suitability for several species

349 in inshore areas, particularly in the fisheries-dependent northwest region. Declining inshore

350 habitat suitability for lumpfish may be particularly challenging for communities where the

351 fishery is a cultural mainstay (Chambers, 2016). The potential movement of lumpfish offshore

352 may present an additional management concern if it increases lumpfish bycatch rates in other

353 fisheries, but could be beneficial if it alleviates interactions with pinnipeds and seabirds. Thus,

354 these multidecadal scale projections might be a consideration in long-term planning not only for

355 fishery development but also broader infrastructure policy, as investment in energy transmission

356 and roads is critical for the competitiveness of smaller and more remote processing facilities

357 (Reynisson et al. 2012).

Further examination of the life history and ecology of these species may aid in

359 interpreting the trends we present here and highlight any results that may warrant further, finer-

360 scale investigation. For example, a potentially puzzling result is that the species with the largest

361 projected suitable habitat decreases, dab and plaice, are both warm-water species. These species

362 are found in shallow waters, and therefore may be particularly sensitive to temperature or limited

363 in their habitat. Survey coverage and timing may also factor into the uncertainty of these results. 
364 For example, dab have an especially patchy distribution with few high-volume tows (MFRI, 2020), which likely reduces model predictive power. Plaice spawn during the early spring, concurrent with the spring surveys (Solmundsson et al., 2005), which may result in aggregations that could bias the survey. These spawning dynamics may in part explain why plaice show a different pattern from lemon sole, another warm and shallow water species that spawns later in the year. While our analyses were intended as an exploration of overall trends rather than fitting individual models for each species, a more tailored approach that incorporates these specific

371 spawning dynamics would be advisable for any planning regarding these species. Similarly, a

372 species-specific approach could reveal climate sensitivity in species we dropped from analysis

373 based on MASE performance. For example, Greenland halibut appear to be sensitive to the

374 interaction between bottom temperature and depth based on model performance in initial trials.

In addition to refining habitat models, more complex approaches are likely needed to accurately project future fish productivity and distribution in Iceland's waters. Our estimates of suitable thermal habitat represent maximum potential abundances with all other factors held

378 equal, and do not capture changes in physiology, species interactions, or fishing pressure, all of 379 which could change in coming decades. Predator-prey interactions could be a dominant 380 ecological driver in Iceland's waters: During the mid-1990s warming period, increasing cod and 381 other gadoid stocks along Iceland's northern coast is believed to have triggered the decline of a 382 commercially important shrimp fishery, as these fish preyed heavily on northern shrimp and 383 other species in closed fjord systems (Jónsdóttir et al., 2019). More recently, mackerel predation 384 has been associated with declines in other warm-water species despite continued warming 385 (Valtýsson \& Jónsson, 2018). Such predator-prey interactions, while not accounted for in our models, would be key management considerations under warming conditions. 
Additionally, we did not differentiate size or age classes among species, nor other

intraspecific population structures that may have distinct suitable thermal habitats and thus future

climate-driven dynamics. Cod, for example, exhibit ontogenetic regional shifts that follow the

clockwise flow of currents around Iceland (Astthorsson et al., 2007), as well as behavioral interactions and fisheries productivity.

Another limitation of our study is that as the survey data are limited to Iceland's EEZ,

397 they may not capture the full thermal or depth range for these species. Thus, our

Western and Southern areas of the International Council for Exploration of the Sea International of straddling stocks and informing priorities for international negotiations. 
410

411

412

413

414

415

416

417

418

419

420

421

422

423

424

425

426

427

428

429

430

431

432

433

that could be important to develop or to protect, but the future outcomes will depend largely on human actions. This study demonstrates the value of using global climate models to make spatially explicit projections of fish suitable habitat, which may serve as guideposts for long-term scenario planning, investment in fisheries and infrastructure, and risk evaluation. For Iceland and other regions with available data to support habitat modeling, such forward-looking studies could be a valuable strategy for achieving climate-adaptive fisheries.

\section{Data statement}

NOAA High Resolution SST data were provided by the NOAA/OAR/ESRL PSL, Boulder, Colorado, USA, from their website at https://www.ncdc.noaa.gov/oisst. GLORYS data were provided by the Copernicus Marine Environmental Monitoring Service at https://resources.marine.copernicus.eu/?option=com_csw\&view=details\&product_id=GLOBAL _REANALYSIS_PHY_001_031.

Code for downloading climate data and performing these analyses is available at https://github.com/juliagmason/iceland_climate_resilient_fisheries.

\section{References}

Abrahms, B., Welch, H., Brodie, S., Jacox, M. G., Becker, E. A., Bograd, S. J., Irvine, L. M., Palacios, D. M., Mate, B. R., \& Hazen, E. L. (2019). Dynamic ensemble models to predict distributions and anthropogenic risk exposure for highly mobile species. Diversity and Distributions, 25(8), 1182-1193.

Allouche, O., Tsoar, A., \& Kadmon, R. (2006). Assessing the accuracy of species distribution models: Prevalence, kappa and the true skill statistic (TSS). Journal of Applied Ecology, 43(6), 1223-1232. 
Anandhi, A., Frei, A., Pierson, D. C., Schneiderman, E. M., Zion, M. S., Lounsbury, D., \& Matonse, A. H. (2011). Examination of change factor methodologies for climate change impact assessment. Water Resources Research, 47(3). https://doi.org/10.1029/2010WR009104

Astthorsson, O., Gislason, A., \& Jonsson, S. (2007). Climate variability and the Icelandic marine ecosystem. Deep Sea Research Part II: Topical Studies in Oceanography, 54(23-26), 2456-2477.

Astthorsson, O. S., \& Palsson, J. (2006). New fish records and records of rare southern species in Icelandic waters in the warm period 1996-2005. ICES CM, 100, 20.

Astthorsson, Olafur S., Valdimarsson, H., Gudmundsdottir, A., \& Óskarsson, G. J. (2012). Climate-related variations in the occurrence and distribution of mackerel (Scomber scombrus) in Icelandic waters. ICES Journal of Marine Science, 69(7), 1289-1297. https://doi.org/10.1093/icesjms/fss084

Chambers, C. P. (2016). FISHERIES MANAGEMENT AND FISHERIES LIVELIHOODS IN ICELAND. University of Alaska Fairbanks.

Cheung, W. W. L., Lam, V. W. Y., Sarmiento, J. L., Kearney, K., Watson, R., \& Pauly, D. (2009). Projecting global marine biodiversity impacts under climate change scenarios. Fish and Fisheries, 10(3), 235-251. https://doi.org/10.1111/j.1467-2979.2008.00315.x

Duan, Naihua (1983). "Smearing Estimate: A Nonparametric Retransformation Method." Journal of the American Statistical Association 78, no. 383: 605-10. https://doi.org/10.1080/01621459.1983.10478017.

Edvardsson, Kristinn Nikulás, Cezara Păstrăv, and Karl Benediktsson. "Mapping the Geographical Consolidation of Fishing Activities in Iceland during the Maturation of the ITQ Fisheries Management System.” Applied Geography 97 (August 2018): 85-97. https://doi.org/10.1016/j.apgeog.2018.05.013.

Eyring, V., Bony, S., Meehl, G. A., Senior, C. A., Stevens, B., Stouffer, R. J., \& Taylor, K. E. (2016). Overview of the Coupled Model Intercomparison Project Phase 6 (CMIP6) experimental design and organization. Geoscientific Model Development, 9(5), 19371958. https://doi.org/10.5194/gmd-9-1937-2016

FAO. (2020). The State of World Fisheries and Aquaculture 2020 (Sustainability in Action). FAO. https://doi.org/10.4060/ca9229en

Fredston-Hermann, A., Selden, R., Pinsky, M., Gaines, S. D., \& Halpern, B. S. (2020). Cold range edges of marine fishes track climate change better than warm edges. Global Change Biology, 26(5), 2908-2922. https://doi.org/10.1111/gcb.15035

Free, C. M., Mangin, T., Molinos, J. G., Ojea, E., Burden, M., Costello, C., \& Gaines, S. D. (2020). Realistic fisheries management reforms could mitigate the impacts of climate change in most countries. PLOS ONE, 15(3), e0224347. https://doi.org/10.1371/journal.pone.0224347

Gaines, S. D., Costello, C., Owashi, B., Mangin, T., Bone, J., Molinos, J. G., Burden, M., Dennis, H., Halpern, B. S., Kappel, C. V., Kleisner, K. M., \& Ovando, B. (2018). Improved fisheries management could offset many negative effects of climate change. Science Advances, 4(8), eaao1378.

Golden, C. D., Allison, E. H., Cheung, W. W. L., Dey, M. M., Halpern, B. S., McCauley, D. J., Smith, M., Vaitla, B., Zeller, D., \& Myers, S. S. (2016). Nutrition: Fall in fish catch threatens human health. Nature, 534(7607), 317-320. https://doi.org/10.1038/534317a 
Grabowski, T. B., Thorsteinsson, V., McAdam, B. J., \& Marteinsdóttir, G. (2011). Evidence of Segregated Spawning in a Single Marine Fish Stock: Sympatric Divergence of Ecotypes in Icelandic Cod? PLOS ONE, 6(3), e17528. https://doi.org/10.1371/journal.pone.0017528

Hijmans, R. J. (2019). geosphere: Spherical Trigonometry. https://CRAN.Rproject.org/package $=$ geosphere

Hijmans, R. J., Phillips, S., Leathwick, J., \& Elith, J. (2020). dismo: Species Distribution Modeling. https://CRAN.R-project.org/package=dismo

Hobday, A. J., Spillman, C. M., Eveson, J. P., Hartog, J. R., Zhang, X., \& Brodie, S. (2018). A Framework for Combining Seasonal Forecasts and Climate Projections to Aid Risk Management for Fisheries and Aquaculture. Frontiers in Marine Science, 5. https://doi.org/10.3389/fmars.2018.00137

Holsman, K. K., Hazen, E. L., Haynie, A., Gourguet, S., Hollowed, A., Bograd, S. J., Samhouri, J. F., \& Aydin, K. (2019). Towards climate resiliency in fisheries management. ICES Journal of Marine Science.

Hoyer, S., \& Hamman, J. (2017). xarray: N-D labeled arrays and datasets in Python. Journal of Open Research Software, 5(1). https://doi.org/10.5334/jors.148

Jónsdóttir, I. G., Bakka, H., \& Elvarsson, B. T. (2019). Groundfish and invertebrate community shift in coastal areas off Iceland. Estuarine, Coastal and Shelf Science, 219, 45-55.

Karp, M. A., Peterson, J. O., Lynch, P. D., Griffis, R. B., Adams, C. F., Arnold, W. S., Barnett, L. A. K., deReynier, Y., DiCosimo, J., Fenske, K. H., Gaichas, S. K., Hollowed, A., Holsman, K., Karnauskas, M., Kobayashi, D., Leising, A., Manderson, J. P., McClure, M., Morrison, W. E., ... Link, J. S. (2019). Accounting for shifting distributions and changing productivity in the development of scientific advice for fishery management. ICES Journal of Marine Science, 76(5), 1305-1315. https://doi.org/10.1093/icesjms/fsz048

Kleisner, K. M., Fogarty, M. J., McGee, S., Hare, J. A., Moret, S., Perretti, C. T., \& Saba, V. S. (2017). Marine species distribution shifts on the US Northeast Continental Shelf under continued ocean warming. Progress in Oceanography, 153, 24-36.

Kleisner, K. M., Ojea, E., Amoros, S., Battista, W., Burden, M., Cunningham, E., Fujita, R., Karr, K., Mason, J., Rader, D., Rovegno, N., Thomas-Smyth, A. (in press). Identifying policy approaches to build social-ecological resilience in marine fisheries with differing capacities and contexts. ICES Journal of Marine Science.

Kokorsch, M., \& Benediktsson, K. (2018). Prosper or perish? The development of Icelandic fishing villages after the privatisation of fishing rights. Maritime Studies, 17(1), 69-83.

Lam, V. W. Y., Cheung, W. W. L., Reygondeau, G., \& Sumaila, U. R. (2016). Projected change in global fisheries revenues under climate change. Scientific Reports, 6(1), 32607. https://doi.org/10.1038/srep32607

Marine and Freshwater Research Institute (2020). Technical report: Dab-Sandkoli (18 pp). https://www.hafogvatn.is/static/extras/images/27-dab_tr1206897.pdf

Molinos, J. G., Halpern, B. S., Schoeman, D. S., Brown, C. J., Kiessling, W., Moore, P. J., Pandolfi, J. M., Poloczanska, E. S., Richardson, A. J., \& Burrows, M. T. (2016). Climate velocity and the future global redistribution of marine biodiversity. Nature Climate Change, 6(1), 83.

Morley, J. W., Frölicher, T. L., \& Pinsky, M. L. (2020). Characterizing uncertainty in climate impact projections: A case study with seven marine species on the North American 
continental shelf. ICES Journal of Marine Science, fsaa103. https://doi.org/10.1093/icesjms/fsaa103

Morley, J. W., Selden, R. L., Latour, R. J., Frölicher, T. L., Seagraves, R. J., \& Pinsky, M. L. (2018). Projecting shifts in thermal habitat for 686 species on the North American continental shelf. PLoS ONE, 13(5). https://doi.org/10.1371/journal.pone.0196127

Mullon, C., Steinmetz, F., Merino, G., Fernandes, J. A., Cheung, W. W. L., Butenschön, M., \& Barange, M. (2016). Quantitative pathways for Northeast Atlantic fisheries based on climate, ecological-economic and governance modelling scenarios. Ecological Modelling, 320, 273-291. https://doi.org/10.1016/j.ecolmodel.2015.09.027

Ogilvie, A. E., \& Jónsdóttir, I. (2000). Sea ice, climate, and Icelandic fisheries in the eighteenth and nineteenth centuries. Arctic, 53(4), 383-394.

Olafsdottir, A. H., Utne, K. R., Jacobsen, J. A., Jansen, T., Óskarsson, G. J., Nøttestad, L., Elvarsson, B. P., Broms, C., \& Slotte, A. (2019). Geographical expansion of Northeast Atlantic mackerel (Scomber scombrus) in the Nordic Seas from 2007 to 2016 was primarily driven by stock size and constrained by low temperatures. Deep Sea Research Part II: Topical Studies in Oceanography, 159, 152-168. https://doi.org/10.1016/j.dsr2.2018.05.023

O’Neill, B. C., Kriegler, E., Ebi, K. L., Kemp-Benedict, E., Riahi, K., Rothman, D. S., van Ruijven, B. J., van Vuuren, D. P., Birkmann, J., Kok, K., Levy, M., \& Solecki, W. (2017). The roads ahead: Narratives for shared socioeconomic pathways describing world futures in the 21st century. Global Environmental Change, 42, 169-180. https://doi.org/10.1016/j.gloenvcha.2015.01.004

Parmesan, C. (2006). Ecological and Evolutionary Responses to Recent Climate Change. Annual Review of Ecology, Evolution, and Systematics, 37(1), 637-669. https://doi.org/10.1146/annurev.ecolsys.37.091305.110100

Pinsky, M. L., Reygondeau, G., Caddell, R., Palacios-Abrantes, J., Spijkers, J., \& Cheung, W. W. (2018). Preparing ocean governance for species on the move. Science, 360(6394), 1189-1191.

Pinsky, M., \& Mantua, N. (2014). Emerging Adaptation Approaches for Climate-Ready Fisheries Management. Oceanography, 27(4), 146-159. https://doi.org/10.5670/oceanog.2014.93

Poloczanska, E. S., Brown, C. J., Sydeman, W. J., Kiessling, W., Schoeman, D. S., Moore, P. J., Brander, K., Bruno, J. F., Buckley, L. B., Burrows, M. T., Duarte, C. M., Halpern, B. S., Holding, J., Kappel, C. V., O’Connor, M. I., Pandolfi, J. M., Parmesan, C., Schwing, F., Thompson, S. A., \& Richardson, A. J. (2013). Global imprint of climate change on marine life. Nature Climate Change, 3(10), 919-925. https://doi.org/10.1038/nclimate1958

Reynisson, Reinhard, Jona Matthiasdottir, Tryggvi Finnsson, and Ari Pall Palsson. "Northeast Iceland Infrastructure Analysis.” Husavik, Iceland: Northeast Iceland Development Agency, 2012.

Saba, V. S., Griffies, S. M., Anderson, W. G., Winton, M., Alexander, M. A., Delworth, T. L., Hare, J. A., Harrison, M. J., Rosati, A., \& Vecchi, G. A. (2016). Enhanced warming of the Northwest Atlantic Ocean under climate change. Journal of Geophysical Research: Oceans, 121(1), 118-132.

Seidov, Dan; Baranova, Olga K.; Biddle, Mathew; Boyer, Tim P.; Johnson, Daphne R.; Mishonov, Alexey V.; Paver, Christopher R.; Zweng, Melissa M. (2013). Greenland- 
Iceland-Norwegian Seas Regional Climatology (NCEI Accession 0112824). NOAA National Centers for Environmental Information. Dataset. https://doiorg.proxy.library.cornell.edu/10.7289/v5gt5k30. Accessed 14-07-2020.

Solmundsson, J., Karlsson, H., Bjornsson, H., Jonsdottir, I. G., Jakobsdóttir, K., \& Bogason, V. (2020). A manual for the Icelandic groundfish survey in spring 2020. Marine and Freshwater Research Institute.

Solmundsson, J., Palsson, J., \& Karlsson, H. (2005). Fidelity of mature Icelandic plaice (Pleuronectes platessa) to spawning and feeding grounds. ICES Journal of Marine Science, 62(2), 189-200. https://doi.org/10.1016/j.icesjms.2004.11.012

Spijkers, J., \& Boonstra, W. J. (2017). Environmental change and social conflict: The northeast Atlantic mackerel dispute. Regional Environmental Change, 17(6), 1835-1851. https://doi.org/10.1007/s10113-017-1150-4

Stefánsdóttir, L. (2008). Groundfish species diversity and assemblage structure in Icelandic waters during a period of rapid warming (1996-2007).

Stefánsdóttir, R. B. (2019). Climate change and northward distribution shifts in Icelandic groundfish species. University of Iceland.

Stefansson, G. (2004). Development of structurally detailed statistically testable models of marine populations (No. QLK5-CT1999-01609; p. 200).

Stefansson, G., \& Palsson, O. K. (1997). BORMICON: A Boreal Migration and Consumption Model (No. 58; p. 233). Marine Research Institute. https://www.hafogvatn.is/static/research/files/fjolrit-058.pdf

Stock, C. A., Alexander, M. A., Bond, N. A., Brander, K. M., Cheung, W. W. L., Curchitser, E. N., Delworth, T. L., Dunne, J. P., Griffies, S. M., Haltuch, M. A., Hare, J. A., Hollowed, A. B., Lehodey, P., Levin, S. A., Link, J. S., Rose, K. A., Rykaczewski, R. R., Sarmiento, J. L., Stouffer, R. J., ... Werner, F. E. (2011). On the use of IPCC-class models to assess the impact of climate on Living Marine Resources. Progress in Oceanography, 88(1), 127. https://doi.org/10.1016/j.pocean.2010.09.001

Sumaila, U. R., Cheung, W. W. L., Lam, V. W. Y., Pauly, D., \& Herrick, S. (2011). Climate change impacts on the biophysics and economics of world fisheries. Nature Climate Change, 1(9), 449-456. https://doi.org/10.1038/nclimate1301

Valdimarsson, H., Astthorsson, O. S., \& Palsson, J. (2012). Hydrographic variability in Icelandic waters during recent decades and related changes in distribution of some fish species. ICES Journal of Marine Science, 69(5), 816-825.

Valtýsson, H. P., \& Jónsson, S. (2018). Impacts of a Changing Climate on Icelandic Marine Stocks. In F. J. Mueter, M. R. Baker, S. C. Dressel, \& A. B. Hollowed (Eds.), Impacts of a Changing Environment on the Dynamics of High-latitude Fish and Fisheries. Alaska Sea Grant, University of Alaska, Fairbanks.

Wood, S. N. (2006). Generalized additive models: An introduction with R,.(Chapman and Hall/CRC: Florida).

Wood, S. N. (2011). Fast stable restricted maximum likelihood and marginal likelihood estimation of semiparametric generalized linear models. Journal of the Royal Statistical Society (B), 73(1), 3-36. 


\section{$614 \quad$ Figures}

615

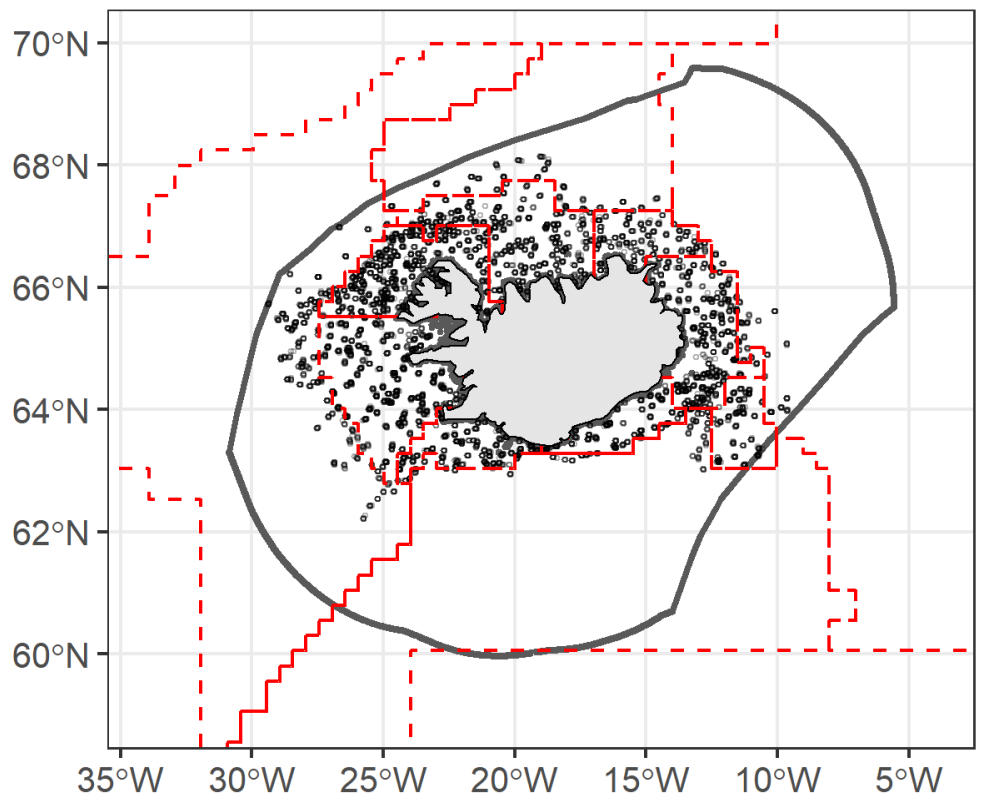

617

Figure 1: Study region indicating Iceland's Exclusive Economic Zone (EEZ, solid line),

618 Bormicon regions (red dashed lines), and bottom trawl survey points. 
Surface temperature
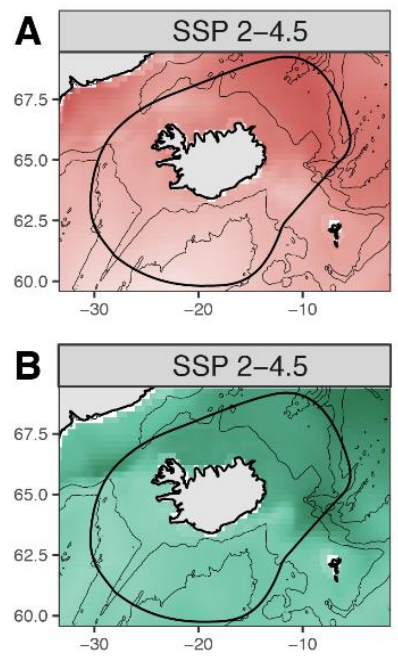
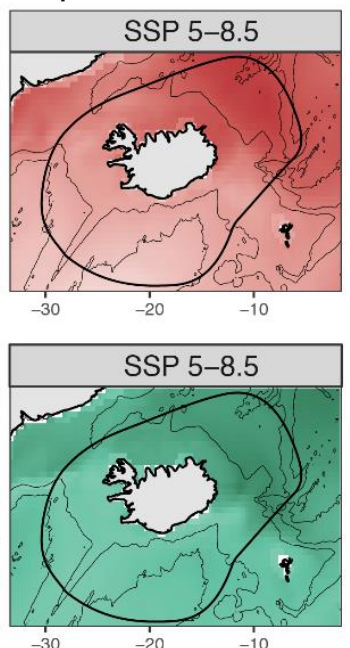

Bottom temperature
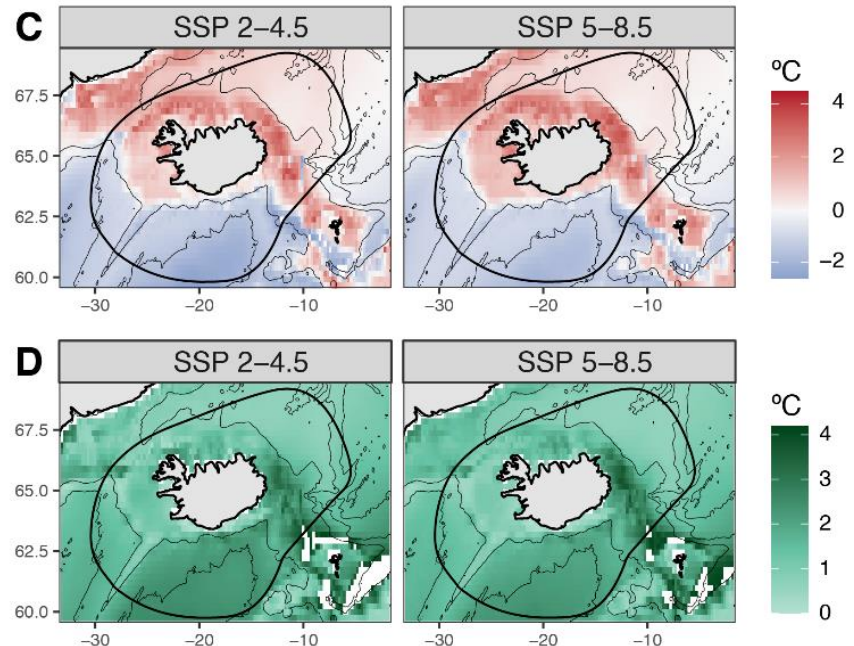

620 Figure 2: Projected ensemble means (A, C) and standard deviation (B, D) for sea surface and 621 bottom temperature deltas for the years 2061-2080 for the middle of the road (SSP 2-4.5) and 622 fossil-fueled development (SSP 5-8.5) scenarios. Thin lines indicate 1000m isobaths and thick 623 lines indicate Iceland's EEZ. 


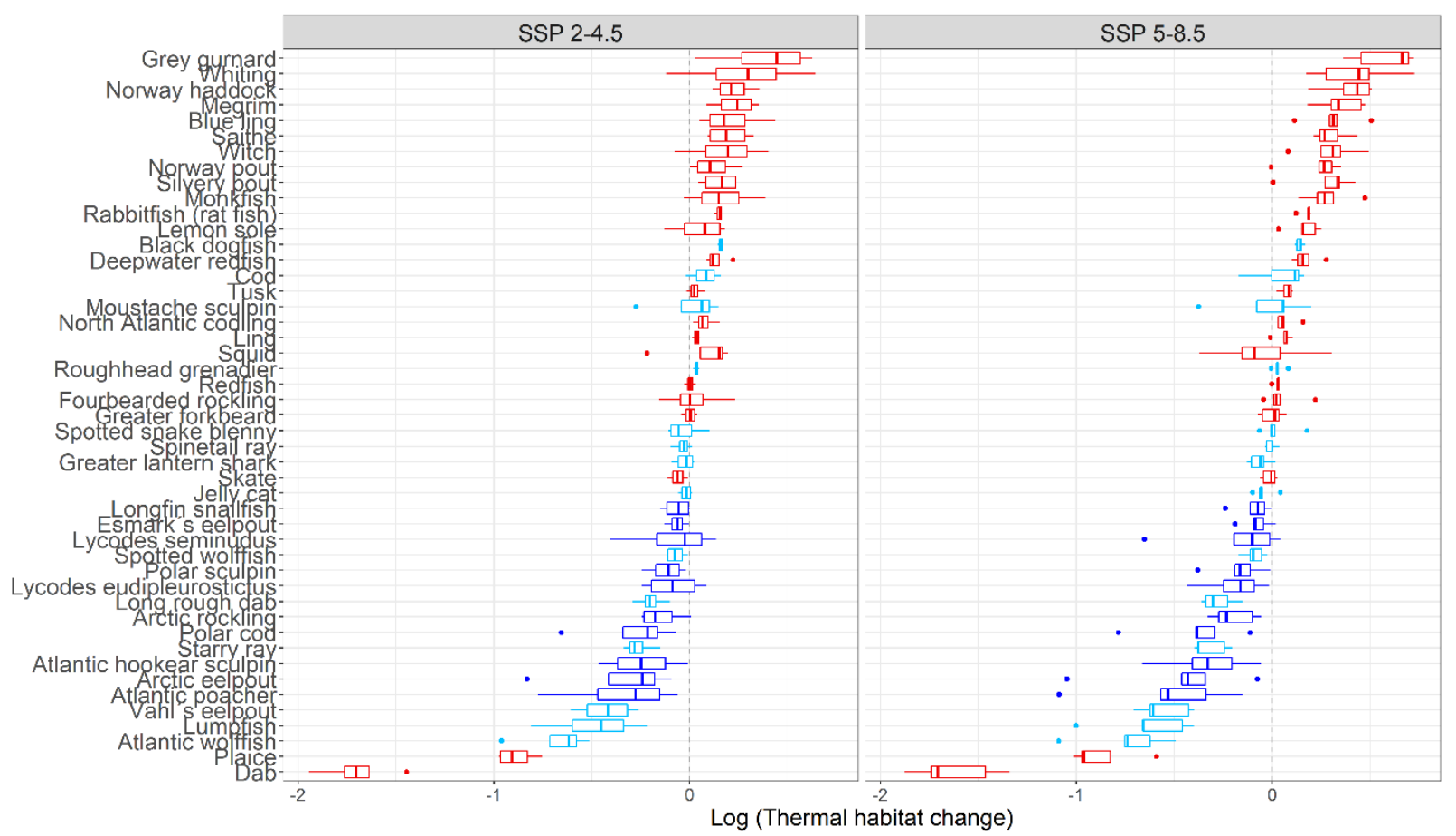

625 Figure 3: Projected changes in suitable thermal habitat for modeled species for 2061-2080

626 relative to 2000-2018 for middle of the road (SSP 2-4.5, left) and fossil-fueled development (SSP

627 5-8.5, right) scenarios. Boxplots represent the distribution of suitable habitat projections from

628 each of the climate models. Colors represent species thermal niche: red species are warm water,

629 light blue are cool water, and dark blue are cold water (see methods and Campana et al., 2020 for

630 classifications). Note that $\mathrm{x}$-axis is on a $\log 10$ scale, so a species with a value of -1 would have

$63110 \%$ of the total projected suitable thermal habitat in 2061-2080 relative to 2000-2018. 

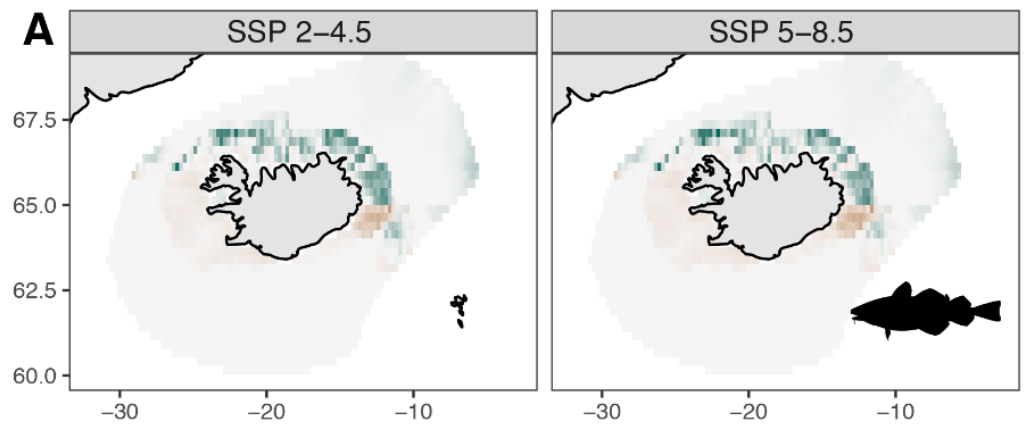

Habitat

difference
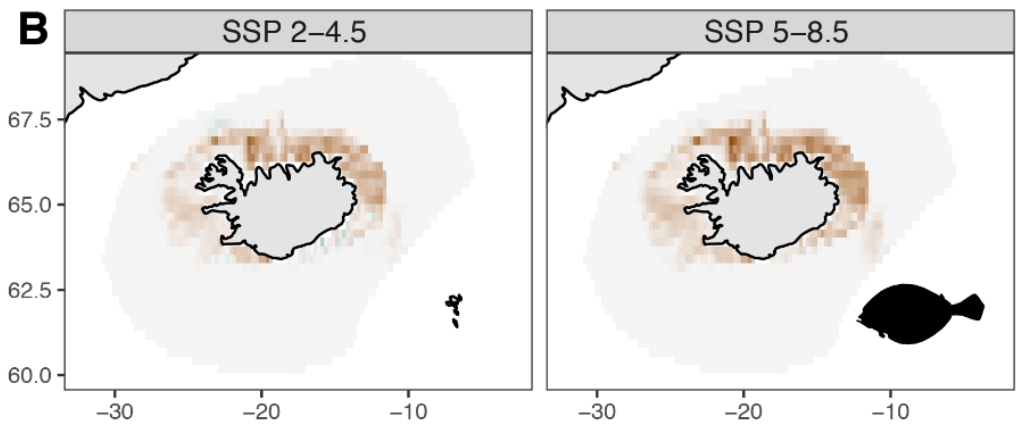

Habitat

difference
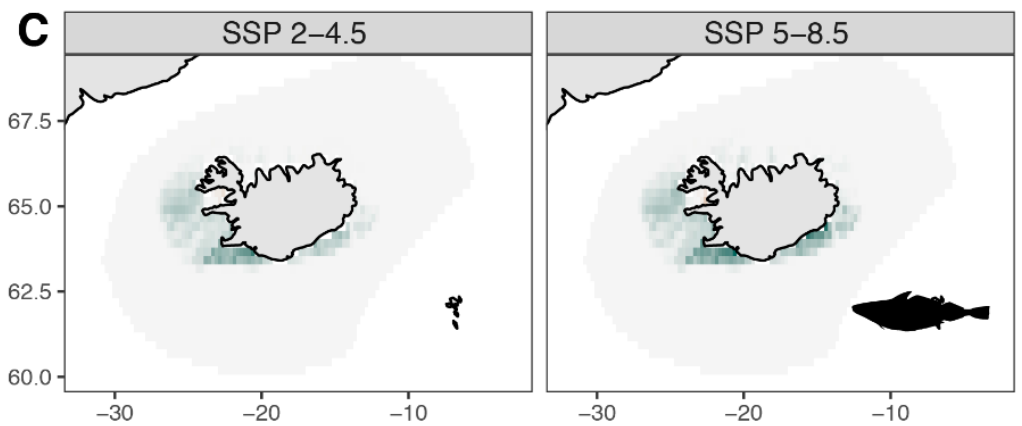

Habitat

difference
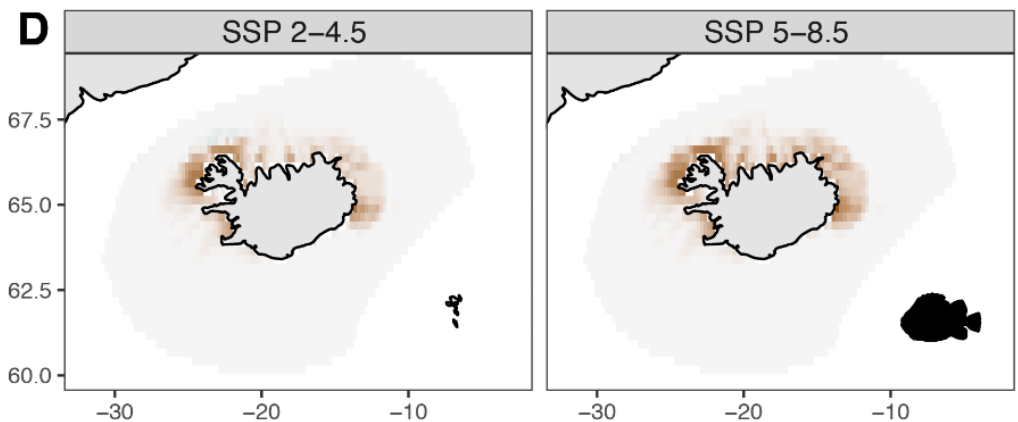

Habitat

difference

Habitat decreasing

\section{Habitat} increasing

633 Figure 4: Projected changes in future habitat suitability for cod (A), long rough dab (B), whiting (C), and lumpfish (D) in 2061-2080 relative to 2000-2018 under the middle of the road (SSP 24.5, left) and fossil fueled development (SSP 5-8.5, right) scenarios. Green regions indicate increases in suitable habitat whereas brown regions indicate decreases in suitable habitat. 


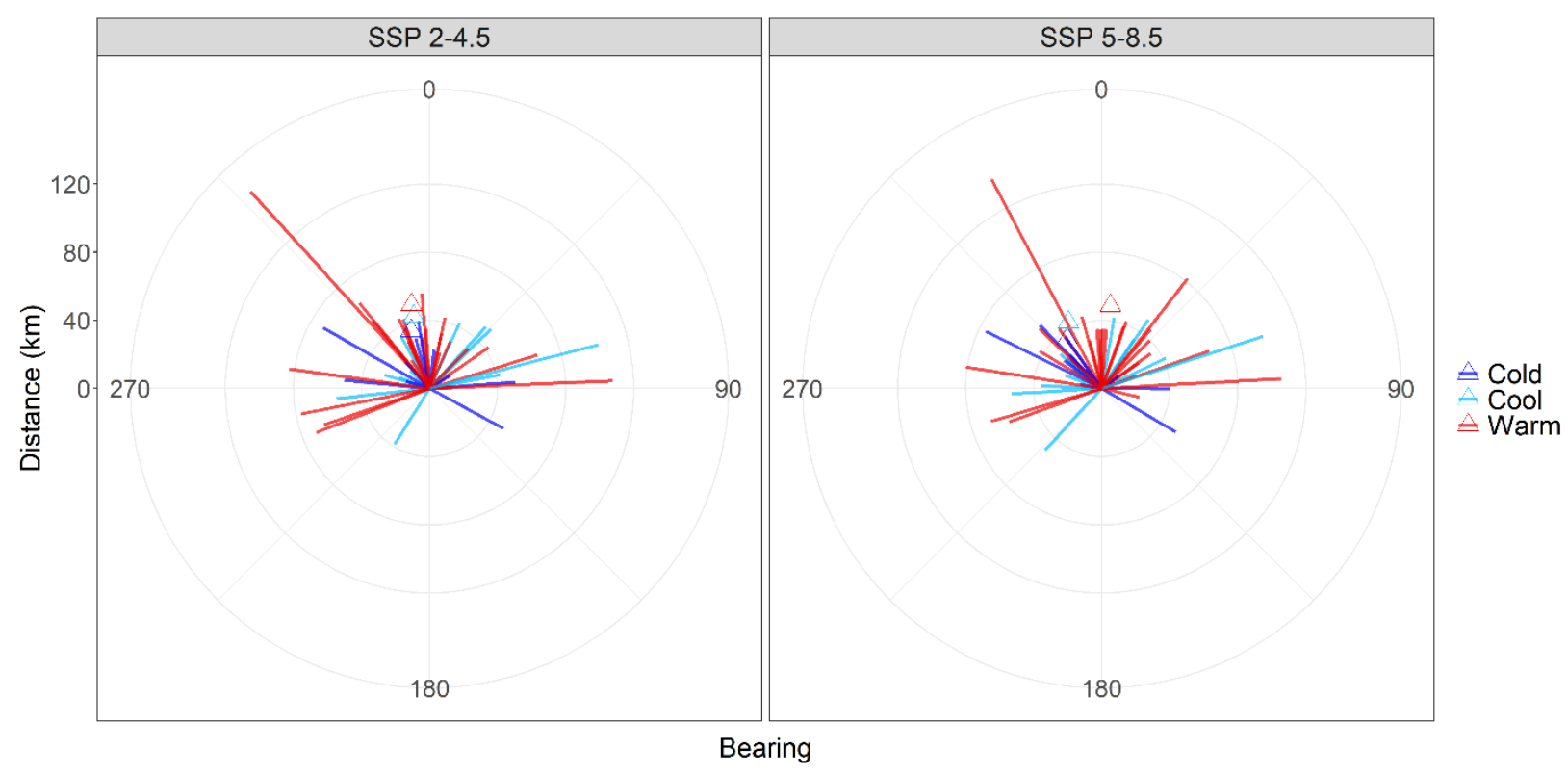

638

639 Figure 5: Projected distance $(\mathrm{km})$ and direction (bearing, 0-360 degrees) of shifts in the centroid 640 of suitable thermal habitat distribution between 2061-2080 and 2000-2018 under the middle of 641 the road (SSP 2-4.5, left) and fossil fueled development (SSP 5-8.5, right) scenarios. Colors

642 represent species thermal niche (see Figure 3). Triangles indicate the circular average value for 643 the bearing change, grouped by thermal niche. Version with species labels available in the 644 supplemental information. 